\title{
Investigation of Correlation Between Diesel Fuel Cold Operability and Standardized Cold Flow Properties
}

\author{
Máté Zöldy ${ }^{1 *}$ \\ 1 Department of Automotive Technologies, Faculty of Transportation and Vehicle Engineering, \\ Budapest University of Technology and Economics, H-1521 Budapest, P.O.B. 91, Hungary \\ * Corresponding author, e-mail: mate.zoldy@auto.bme.hu
}

Received: 04 April 2019, Accepted: 26 April 2019, Published online: 05 July 2019

\begin{abstract}
Role of diesel fuel in the mobility is unquestionable despite of diesel scandal. There are several approaches to substitute partially at least it, but in commercial utilization the real alternative is not found yet. Diesel fuel main disadvantage beside the environmental factors is the application properties in cold weather. In the presented research there is an overview and evaluation about the main classification methods of winter properties of diesel. The result is, that CFPP and CP have lower and lower correlation with the newest engine technologies and a new method would be necessary to able to predict the winter behavior of diesel in real conditions. In the paper a specification of a new test equipment is presented.
\end{abstract}

Keywords

diesel fuel, cold start properties, winter behavior

\section{Introduction}

Role of diesel fuel in the mobility is unquestionable despite of diesel scandal. Short term, mainly urban mobility the electric vehicles could have an increasing role in the future, but in long haul commercial traffic the role of the diesel seems to be unbroken (Pölczmann et al., 2014). There are several approaches to blend fossil diesel with bio components, even with exotic ones (Li et al., 2015), but the main characteristics of diesel fuel is based on the fossil components.

The aim of the presented investigation is to explore the correlation between the diesel fuel standardized cold flow property measurement results and its behavior in real cold conditions. This knowledge is essential to determine winter parameters of diesel fuels that could utilized in the engines of the state of the art in expected winter circumstances.

\section{Vehicle technology}

Winter performance of diesel fuels is one of the most critical application properties. There are lots of factors that have effect on start-ability at cold conditions. The main factors are presented in Table 1.

In the presented research work, the engine and fuel system parameters were handled as capabilities. Besides
Table 1 Vehicle cold startability factors

\begin{tabular}{|c|c|c|}
\hline Factor & $\begin{array}{c}\text { Factor influenced } \\
\text { by... }\end{array}$ & $\begin{array}{l}\text { Main changes } \\
\text { in the last decades }\end{array}$ \\
\hline $\begin{array}{l}\text { design of fuel } \\
\text { line }\end{array}$ & $\begin{array}{l}\text { vehicle \& fuel system } \\
\text { manufacturer }\end{array}$ & none \\
\hline pore size of fuel & fuel system & decrease from \\
\hline filter & manufacturer & 10 micron to 2 micron \\
\hline $\begin{array}{l}\text { presence of } \\
\text { heater in fuel } \\
\text { filter }\end{array}$ & $\begin{array}{l}\text { vehicle \& fuel system } \\
\text { manufacturer }\end{array}$ & none \\
\hline $\begin{array}{l}\text { type of fuel } \\
\text { injector }\end{array}$ & $\begin{array}{l}\text { fuel system } \\
\text { manufacturer }\end{array}$ & $\begin{array}{l}\text { space reduction, } \\
\text { velocity increase }\end{array}$ \\
\hline $\begin{array}{l}\text { injection } \\
\text { pressure of fuel }\end{array}$ & $\begin{array}{l}\text { fuel system } \\
\text { manufacturer }\end{array}$ & $\begin{array}{l}\text { pressure increase from } \\
\text { 3-600 bar up to } 2700 \text { bar } \\
\text { (Knight et al., 2012) }\end{array}$ \\
\hline $\begin{array}{l}\text { compression } \\
\text { pressure in } \\
\text { cylinder }\end{array}$ & engine manufacturer & slightly increase \\
\hline engine oil & $\begin{array}{c}\text { lubricant } \\
\text { manufacturer }\end{array}$ & none \\
\hline $\begin{array}{l}\text { cold property } \\
\text { of fuel }\end{array}$ & fuel producer & none \\
\hline
\end{tabular}

all these, it would not hurt to state that compression ignition engine technology development is accompanied with the change of the whole fuel system including fuel filters, 
injectors and pumps as well. Continuous development of fuel injection system, for example the increasing injection pressures of the common rail technology, the correlation between the analytical measurement of diesels winter qualities as Cold Filter Plugging Pint (CFPP) of fuel and real world operability is getting weaker.

In the presented work the main focus is to determine the correlation between operation point and the standardized features as CFPP or cloud point (CP) etc. Sufficient cold flow behavior is one of the most important quality measures for diesel fuels and it bases on three pillars:

- Distillation range, within this back-end volatility;

- Composition: aromatics, naphthenes and paraffins content

- and utilization of cold flow improver additives.

The composition of the diesel massively changed in the last decade. Sulphur content had to decrease less than $10 \mathrm{ppm}$ based on the emission needs and the request of automotive manufacturers. Bio components are emerged (Bereczky, 2012; Sági et al., 2017). Aromatic content was cut back based on health reasons. These product quality changes had a great influence on the diesel production process and on cold flow characteristics. Refining processes has been changed to produce low sulphur diesel fuels. Paraffinic hydrocarbons can be removed from the fuel with catalytic cracking and hydro-desulfurization processes, it changes the size and form of the crystals in the diesel, these processes reducing the aromatic content of the fuel as well and they had a negative effect on lubricity, and decreasing diesels ability to dissipate static electricity (Porter, 2012).

These changes in fuel characteristics including higher temperature crystalizing, wax dropout, icing, and difficulty in treating will continue into the near future at unusual cold conditions to deliver some remarkable challenges to fuel wholesalers and end customers during winter.

Paraffin wax is a natural and main component of the fossil fuel of compression ignition engines. It delivers numerous advantageous characteristics including increased specific energy content, lubricity, storage stability and viscosity. It has some disadvantages as well, mostly at cold weather operation and inclined to gel forming and wax dropout (Porter, 2012).

\section{Critical cold flow temperatures}

The bottommost temperature, where the fuel can move under given circumstances called Pour point (PP). The mechanics makes happen the diesel oil not to move pour

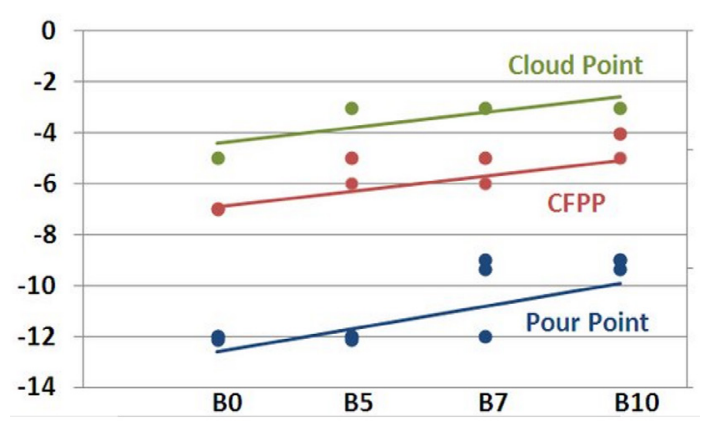

Fig. 1 Typical diesel cold flow properties (Teixeira et al., 2013)

is due again to the constant development and subsequent binding of waxes into a macroscopic gel, thereby trapping and not letting residual liquid diesel to move. The usefulness of pour point matches with the diesel's pumpability; and it is usability is lower in case of filters are present and hence is not in the scope of our investigations.

For this reason many have fixed the difference between CP and CFPP of their content specification to be within a certain limit. For example, one refiner has specified their diesel's CFPP to be no greater than $8{ }^{\circ} \mathrm{C}$ below the $\mathrm{CP}$, in order to "ensure there is not an excess of fine wax crystals which may be sufficient to block filters" (Tutak et al., 2015).

Fig. 1 shows the typical relation between Cloud point, Cold Filter plugging point and Pour Point in function of diesels biodiesel (FAME) content. It is to see that the difference between CP and CFPP is nearly constant.

Fossil diesel typically contains high amount of paraffin that, if the fuel is cooled adequately, will led to wax formation. Based on this phenomenon, satisfactory performance in cold environment is one of the most important aspects of diesel quality in relation to its performance in the engine. During the cooling of the fuel, it arrives to the temperature at which the separation process of waxes starts and a cloud apprising in the fuel. This temperature called as cloud point (CP) (Lee, 2011).

If fuel is cooled lower than its cloud point, more and more of waxes starts to agglomerate. If the cooling process is continued, after a given temperature decrease the wax starts to cover the fuel filter heavily enough to hinder the diesel flow. The fuel remains useable, before the filter is blocked up to this temperature. It is known as the Cold Filter Plugging Point (CFPP).

In the last decades huge efforts and development was carried out on the field of wax crystal modifier additives. It resulted, that vehicles today can be started up and used at lower ambient temperatures as before. For the fuels that are containing additives for way crystal modifiers the 
CFPP is recognized as a more realistic measure of cold temperature performance. The CFPP is mainly used in the US and European markets (Porter, 2012). Fuels without wax modifier additive Cloud Point remains as the relevant method for determining winter behavior.

Cold flow properties of diesel fuels are defined in Europe in the European Standards (CEN, 1999). It uses as basis the Cold Filter Plugging Point values based on local ambient conditions. EN 590 uses Cloud Point only in addition to CFPP to define the low temperature properties of arctic diesel grades, based on seasonal and locational factors.

There are four main indicators to characterize the diesel fuel behavior at cold conditions. Cloud Point (abbreviated $\mathrm{CP}$ ) is the temperature during the cooling of the fuel at which small solid paraffin crystals are first visually observed: the fuel becomes cloudy. Below this temperature these wax crystals might plug filters or could drop to the bottom of a storage tank. However, fuels can usually be pumped at temperatures below cloud point. Cloud point is measured according to the prescriptions of ISO 3015 and ASTM D2500.

In the US the Low Temperature Flow Test (LTFT) is utilized to forecast diesel fuels cold temperatures performance. It is a slow cooling test and therefore its severity is better than CFPP. Similarly, to CFPP test cold flow additives could influence the LTFT temperature as well. The determination of LTFT is in ASTM D4539.

\section{Literature overview}

Literature study (Porter, 2012) established that, there is a new low temperature problem that the industry has not satisfactorily defined. The issue is called "Wax Dropout". It occurs when diesel fuel reaches during the cooling a given cold temperature and for a longer period stays at this temperature of even below. Critical time is according to the experiences between 48 and 72 hours (Porter, 2012) and the temperature varying with different batches of fuel. This past winter the study detected this phenomenon at between $-15{ }^{\circ} \mathrm{C}$ and $-12{ }^{\circ} \mathrm{C}$.

Some scientific works have studied the correlations between the CP, PP, CFPP, LFTF and operability. In a pioneering study on the utilization of critical temperatures versus the drivability of trucks. Coordinating Research Council (CRC, 2008) investigation resulted that Cloud Point is the most conservative, safe and conservative measure at $98 \%$ of the cases it predicts the lowest operating temperature of the tested vehicles, while the second best LTFT had prediction level of $89 \%$, and CFPP as worst, $64 \%$ of the time.
According to the statements of Lee (2011) the cloud point undervalues vehicle operability temperature but pour point overvalues it. Cold filter Plugging Point had high level of correlation with vehicle operability. Research proposed the introduction of a new index, called b-CFPP. The main idea behind this new approach is in case of diesel is stored in cold weather, wax crystals in most of the cases agglomerate in bottom layer.

The new index handles that the cold properties of upper and bottom layer are not equal. During the determination of b-CFPP the bottom fifth of the test sample is utilized for CFPP measurement after storing the fuel at $-15{ }^{\circ} \mathrm{C}$ for 16 hours.

Another study (Chandler and Zechman, 2000) presents result measurements done on newer-generation heavy-duty vehicles. They results are in line with $(\mathrm{CRC}, 2008)$ at cold ambient temperatures, LTFT test predicted the results correctly $78 \%$ of the time, while CFPP prediction was around $65 \%$ correct.

Coordinating Research Council study from 2008 (CRC, 2008) concluded that cloud point was able to predict in an accurate way the minimum operating temperature (EMOT). According to these results, CFPP is able to predict an operability limit higher than cloud point. LTFT was conservative in all cases, but in case of some test vehicles the reserve was too huge.

Diesel specification of the European Union (CEN EN-590), specifies both CP and CFPP in its winter grade (arctic) diesels, but have a special limitation, that CFPP cannot be lower more than $10^{\circ} \mathrm{C}$ by $\mathrm{CP}$. This is in line with the $20135^{\text {th }}$ edition of World-Wide Fuel Charter's (WWFC proposal. It is set of harmonized proposal for fuel quality under the patronages of vehicle manufacturers all over the world. The WWFC therefore represents the consensus of most of the automotive and engine producers and trade associations in the world. It agrees all of CP, LTFT, and CFPP to serve as compliance parameter. In case of a separate utilization of either Cloud Point or LTFT, the highest tolerable temperature should be set no higher than the deepest expected external temperature. In case of CFPP is used to predict cold flow standalone, the maximum acceptable CFPP temperature should be set equal to, or lower than, the lowest expected external temperature. In this case, the Cloud Point should be no more than $10^{\circ} \mathrm{C}$ above the CFPP specified. The WWFC solves this with the approach by declaring that only CFPP cannot describe the cold flow performance precisely.

A paper from France reported (Faucon et al., 2009) about the winter 2008-2009 shows example when fuel 
met the EN 590 prescriptions and the vehicle filter were plugged. High levels of saturated monoglycerides were found in the filters that did not re-dissolve in the fuel. The CFPP test was not able to detect the problem due to the fast cooling and new methods have to be developed to better address the issue.

The proposal of an US study (Enertech Labs, 2014) suggest a solution, that can be utilized in the time horizon, until a new test method is developed for determining the relationship between CFPP, PP, CP and filter media size for $10 \mathrm{ppm}$ diesel, based on the vehicle filter fineness. Table 2 shows the connection between the diesel fuel opearition point and bore diameter of the filter.

Lakatos' investigations were focusing on public mobility, on environment protection and economic operation. The vehicle start up and operational procedure at cold ambient circumstances in case of buses must be optimized both in the aspects of environment protection and economic operation. With the management of these factors an analysis was carried out to investigate most relevant factors and a measuring system was elaborated for fuel consumption as well. Based on the measurement of fuel consumption a new operational procedure (Lakatos, 2015) was suggested. Importance of emissions is highlighted in (Rimkus et al., 2013; Taritas et al., 2017; Szwaja et al., 2018; Juknelevicius et al., 2018) as well.

Vehicle emissions legislative background continues to become more rigorous aiming to reduce the traditional compression and spark ignition engines impact on the environment (Török, 2018). One focal area of this development is the cold start behavior of engines and vehicles.

Internal combustion engine thermal efficiency is considerably worse at cold start than when vehicle operation reaches nearly steady state temperatures. Thermal efficiency management both for the engine and for the vehicle as well has led to a numerous solutions being tested to evaluate their advantages and effects on automotive systems during this cold start and the following warm-up phase. The common standpoint of the approaches is that

Table 2 Diesel fuel operation point determination in function of filter pore diameter (Chandler and Zechman, 2000)

\begin{tabular}{lc}
\hline $\begin{array}{l}\text { Filter bore diameter } \\
{[\text { micro } \mathrm{m}]}\end{array}$ & Operation Point determination method \\
\hline 10 & OP10 = midpoint between PP and CFPP \\
7 & OP7 $=$ midpoint between PP and CFPP \\
5 & OP5 $=$ take the midpoint between that number \\
& and the original CP $=(\mathrm{OP} 10+\mathrm{CP}) / 2$ \\
2 & use the CP \\
\hline
\end{tabular}

they aim to minimize energy losses until the engine and vehicle components reach their planned operating temperature range. In case of internal combustion engine, the main focus is on the lubricant system. As lubricants, mainly engine and clutch oils, viscosity are heavily temperature dependent, the fast warm up can easily decrease the high viscosity based increased frictional and pumping losses. The provided solution aiming to reduce cool-down rate following the engine running with the utilization of phase change materials and heat loss prevention with thermal barrier coatings (Roberts et al., 2014).

Summarized the literature experiences the main findings are the following: CFPP was a valid reference measurement of fuels winter quality for many years in the case of moderate sulphur containing diesel fuels. Most diesel fuel filters were 10 micrometers there was a good correlation between CFPP and the temperature at which a standard fuel filter would plug. However the relationship is much different between the improved bore diameter and maximal 10 ppm sulphur containing diesel. Previously 10 um has been almost an industry standard, and now is not uncommon to see $7 \mathrm{um}, 5 \mathrm{um}$, and even 2 um fuel filters. This development of the filters throws the relationship between CFPP and cold weather operability more than questionable. For the determination of the diesel fuel in cold temperatures, the elaboration of a new method is necessary. Based on the experiences the aim of our research is to define the prerequisites of new measurement method.

\section{Conclusions and proposed solution}

As the main difficulty with the traditional CFPP method is the incompatibility of the fuel filter diameter change, our approach aims to have a set up that can follow the technological changes within the automotive industry. It should contain all elements of a state-of-the art fuel supply system.

The method should be capable to used with test fuels and fuel samples from different development phases as well. It needed to be operated intermittent and be able to cooled down to different temperature grades. As best fuels in the European market nowadays are reaching $-35^{\circ} \mathrm{C}$ or even $-40{ }^{\circ} \mathrm{C}$ CFPP, it should be able to be cooled down at least to this temperature range. Data acquisition system should be an integrated element of the system, compatible with commonly used data process systems. Filters should be easily changeable for comparison tests.

For this specification we defined a technical solution, it is to see on Fig. 2. 


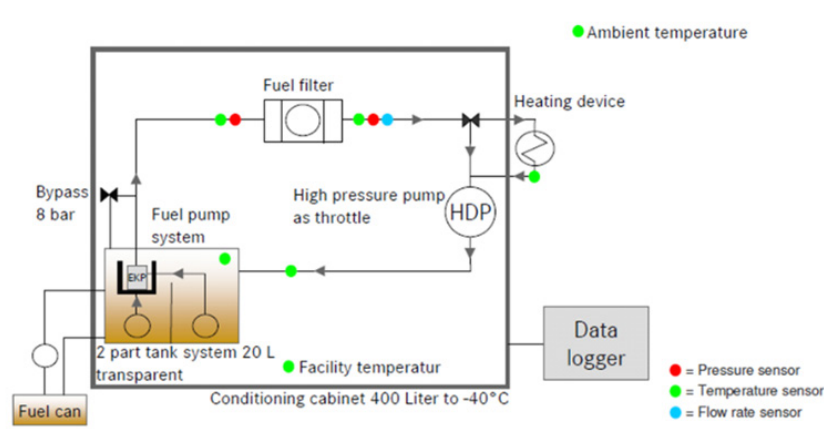

Fig. 2 Proposed new diesel cold start measurement system

Frame of the system is a deep freezer chest. It allows reaching and keeping the test temperatures with the highest energy efficiency. As the main elements of the common rail fuel supply system a fuel tank, pre-pump, fuel

\section{References}

Barabas, I., Todorut, I.-A. (2011) "Biodiesel Quality, Standards and Properties" In: Montero, G. (ed.) Biodiesel - Quality, Emissions amd By-Products, 1st ed., InTech, Rijeka, Croatia, pp. 3-28. https://doi.org/10.5772/25370

Bereczky, Á. (2012) "Alternative Fuels and Technologies for Compression Ignition Internal Combustion Engines", Journal of KONES: Powertrain And Transport, 19(4), pp. 43-52. https://doi.org/10.5604/12314005.1138306

Chandler, J., Zechman, J. (2000) "Low-Temperature Operability Limits of Late Model Heavy-Duty Diesel Trucks and the Effect Operability Additives and Changes to the Fuel Delivery System Have on Low-Temperature Performance", SAE Mobilus, Technical Paper 2000-01-2883.

https://doi.org/10.4271/2000-01-2883

Coordinating Research Council, CRC (2008) "Biodiesel Blend LowTemperature Performance Validation", Coordinating Research Council, Alpharetta, GA, USA, Rep. 656.

European Committee for Standardization, CEN (2010) "EN 590 Automotive fuels - Diesel - Requirements and Test Methods", CEN, Brussels, Belgium, 2010.

Faucon, R., Gendron, A., Cottalorda, O. (2009) "Diesel Fuel B7 Specifications Need to be Reinforced for Cold Weather Conditions", presented at World Refining Fuels Conference, Brussels, Belgium, May 9, 2009.

Juknelevicius, R., Szwaja, S., Pyrc, M., Gruca, M. (2019) "Influence of hydrogen co-combustion with diesel fuel on performance, smoke and combustion phases in the compression ignition engine", International Journal of Hydrogen Energy, 44(34), pp. 19026-19034. https://doi.org/10.1016/j.ijhydene.2018.10.126

Knight, A., Crossley, S., Draper, D. E. (2012) "Development of high pressure common rail systems incorporating advanced electronic control strategies for future heavy duty vehicles" In: 33rd International Vienna Motor Symposium, Vienna, Austria, pp. 216-233. [online] Available at: https://www.tib.eu/en/search/ id/tema\%3ATEMA20120900485/Development-of-high-pressurecommon-rail-systems/ [Accessed: 25 April 2019] filter and high pressure pumps are needed. Fuel tank should be transparent to able to see the quality changes within the tank. High pressure pump as a system choke should be the part of the setup. All technology should be inserted into a bund. The technology should be prepared for biodiesel content of the diesel fuel, what is according to the regulation in normal cases cannot reach 7 volumetric percent (Barabas and Todorut, 2011). Pressure and temperature sensors are necessary according to presented into the Fig. 2 to able to follow and document the status of the fuel and the system.

With the proposed system a real world utilization near test environment can be developed in which the fuel behaves in the same way as it is in the vehicles.

Lakatos, I. (2015) "Development of a New Method for Comparing the Cold Start- and the Idling Operation of Internal Combustion Engines", Periodica Polytechnica Transportation Engineering, 43(4), pp. 225-231.

https://doi.org/10.3311/PPtr.8087

Lee, J.-S. (2011) "The Modified - treatment study of WAFI for the Cold Property Control in Winter Season", presented at Advances in Refining and Catalytic Technologies, Fuel Quality and Alternative Energy, The 4th Japan-China-Korea Petroleum Technology Congress, Tokyo, Japan, Febr. 22-23, 2011.

Li, C., Zhang, L., Xiao, Z., Li, P., Liu, R., Chen, J., He, Z., Fu, J. (2015) "Production of Biodiesel Using a Vegetable Oil from Swida wilsoniana Fruits", Periodica Polytechnica Chemical Engineering, 59(4), pp. 283-287. https://doi.org/10.3311/PPch.7868

Pölczmann, Gy., Tóth, O., Beck, Á, Hancsók, J. (2014) "Storage Stability of Gas Oils Containing Waste Originated Biocomponent", Periodica Polytechnica Chemical Engineering, 58(2), pp. 157-163. https://doi.org/10.3311/PPch.7205

Porter, S. (2012) "Diesel cold flow problems and early warning indicators", Today's Trucking, [online] Posted: 1 Aug. 2014, Available at: https://www.todaystrucking.com/diesel-cold-flow-problems-andearly-warning-indicators/ [Accessed: 25 April 2019]

Rimkus, A., Pukalskas, S., Matijošius, J., Sokolovskij, E. (2013) "Betterment of ecological parameters of a diesel engine using Brown's gas", Journal of Environmental Engineering and Landscape Management, 21(2), pp. 133-140. https://doi.org/10.3846/16486897.2012.679661

Roberts, A., Brooks, R., Shipway, P. (2014) "Internal combustion engine cold-start efficiency: A review of the problem, causes and potential solutions", Energy Conversion and Management, 82, pp. 327-350. https://doi.org/10.1016/j.enconman.2014.03.002 
Sági, D., Solymosi, P., Holló, A., Varga, Z., Hancsók, J. (2017) "Production of diesel fuel blending components from waste and conventional sources", In: Fourth International Conference Catalysis For Renewable Sources: Fuel, Energy, Chemicals (CRS-4), Gabicce Mare, Italy, pp. 75-76.

Szwaja, S., Ansari, E., Rao, S., Szwaja, M., Grab-Rogalinski, K., Naber, J. D., Pyrc, M. (2018) "Influence of exhaust residuals on combustion phases, exhaust toxic emission and fuel consumption from a natural gas fueled spark-ignition engine", Energy Conversion and Management, 165, pp. 440-446.

https://doi.org/10.1016/j.enconman.2018.03.075

Taritas, I., Sremec, M., Kozarac, D., Blažić, M., Lulic, Z. (2017) "The Effect of Operating Parameters on Dual Fuel Engine Performance and Emissions - An Overview", Transactions of FAMENA, 41(1). https://oi.org/10.21278/TOF.41101

Teixeira, R. M., de Castro Cortás, L., Viscardi, S. L. C., Cavalcanti, E. H. S. (2013) "Impact of biodiesel on filterability and cold flow properties of diesel BX", In: IASH 2013, the 13th International Conference on Stability, Handling and Use of Liquid Fuels, Rhodes, Greece, 2013, pp. 628-644.
Török, Á. (2018) "Elhárítási határköltség görbék alkalmazása a jármügépészeti fejlesztések priorizálásában" (Applying remedial marginal cost curves to prioritize vehicle engineering developments), In: XXVI. Nemzetközi Gépészeti Konferencia, OGÉT 2018, Targu Mures, Romania, pp. 508-511. (in Hungarian)

Tutak, W., Lukács, K., Szwaja, S., Bereczky, Á. (2015) "Alcohol-diesel fuel combustion in the compression ignition engine", Fuel, 154, pp. 196-206. https://doi.org/10.1016/j.fuel.2015.03.071

Enertech Labs (2014) "Ultra-Low Sulfur Diesel Fuel Cold Weather Information", [online] Available at: https://enertechlabs.com/ultra-low-sulfur-diesel-fuel-cold-weather-information/ [Accessed: 25 April 2019]

OICA (2006) "Worldwide Fuel Charter", 4th ed., Paris, France. [online] Available at: http://oica.net/wp-content/uploads/2007/06/wwfcfourth-edition-sep-2006.pdf [Accessed: 25 April 2019] 